\title{
Effect of cooling and freezing, the two first steps of a freezing protocol, on the fertilizing ability of the rabbit sperm
}

\author{
Eva Mocé*, José Salvador VICENTE \\ Biotechnology Reproduction Laboratory, Department of Animal Science, \\ Polytechnical University of Valencia, Camino de Vera s/n, 46071 Valencia, Spain
}

(Received 22 February 2002; accepted 7 May 2002)

\begin{abstract}
The effect of different phases of a freezing protocol on the fertilising ability of rabbit spermatozoa was evaluated. An extender containing $1.75 \mathrm{M}$ DMSO and $0.05 \mathrm{M}$ sucrose (final concentration) was used to freeze rabbit sperm. In the first experiment, the results obtained with fresh and cooled $\left(5^{\circ} \mathrm{C}\right.$ for $45 \mathrm{~min}$ ) sperm were compared; no differences were observed between fresh and cooled semen for any of the parameters studied: fertility rate $(78 \%$ vs. $91 \%$ for fresh and cooled sperm, respectively), and normal embryos two days after insemination (6.8 vs. 8.5 normal embryos for fresh and cooled sperm). In the second experiment, the results obtained with fresh semen and sperm which had passed the first two steps of a freezing protocol $\left(5^{\circ} \mathrm{C}\right.$ for $45 \mathrm{~min}$ and $-30{ }^{\circ} \mathrm{C}$ for $30 \mathrm{~min}$, and thawed at $50{ }^{\circ} \mathrm{C}$ for $15 \mathrm{~s}$ ) were compared; the differences between them were obtained for fertility rate (94\% vs. $61 \%$ for fresh and frozen sperm, respectively) and normal embryos two days after insemination ( 7.8 vs. 3.8 fresh and frozen sperm). These observations indicated that the differences in the results obtained with fresh and cryopreserved sperm were produced during the second step of the freezing protocol, and that apparently no toxic effect of DMSO was produced.
\end{abstract}

embryo / fertility / freezing / rabbit / sperm

\footnotetext{
* Correspondence and reprints

E-mail: emoce@dca.upv.es
} 


\section{INTRODUCTION}

Although several authors have developed different extenders and protocols for freezing rabbit sperm, in general the results on fertility and prolificity are not comparable to those obtained with fresh sperm. Most of the extenders have egg yolk in their composition, and different combinations of cryoprotectants are added at different concentrations. Some of the cryoprotectants that have been used are dimethyl sulfoxide, glycerol, ethylene glycol, acetamide, trehalose, methyl cellulose, sucrose or skimmed milk $[1,2,3,6,8,13,16,18,19,22]$.

Most of the protocols need long periods of cooling (between 2 and $4 \mathrm{~h}$ ) before they are frozen, which makes the protocol very tedious. In 1996, Vicente and Viudes de Castro [19] developed a rapid protocol for freezing rabbit sperm $\left(30 \mathrm{~min}\right.$ at $5{ }^{\circ} \mathrm{C}$, and $15 \mathrm{~min}$ at $-30^{\circ} \mathrm{C}$, using straws of $0.25 \mathrm{~mL}$ ), using an extender with Tris and citric acid, without egg yolk and supplemented with $0.05 \mathrm{M}$ sucrose and $1.75 \mathrm{M}$ DMSO (final concentrations); the results obtained both in fertility and prolificity for the New Zealand White rabbits were comparable to those obtained with fresh sperm (fertility rate: $81 \%$ vs. $79 \%$ for fresh and frozen sperm, respectively, and 8.1 vs. 8 total born for fresh and frozen sperm, respectively, [20]). The following attempts to inseminate with sperm which had been frozen with this protocol with slight modifications (straws of $0.5 \mathrm{~mL}, 45 \mathrm{~min}$ at $5^{\circ} \mathrm{C}$ and $30 \mathrm{~min}$ at $-30{ }^{\circ} \mathrm{C}$ ) on a commercial farm, and using animals belonging to different genetic strains, did not give the expected results (a $50 \%$ fertility rate and 6.9 total born $[10,11]$ ).

The aim of these experiments was to study the effect of the different phases of a freezing protocol of rabbit semen (after cooling and after freezing-thawing, before being plunged into liquid nitrogen) on the fertilising ability of the spermatozoa, using the extender developed by Vicente and Viudes de Castro [19].

\section{MATERIALS AND METHODS}

\subsection{Animals}

Three adult males were used for the experiments. They belonged to a synthetic maternal line selected for litter size at weaning [4].

Eighty-two receptive females were used in the experiments: 46 of them were used to evaluate the toxicity of the freezing extender after cooling and 36 to evaluate the toxicity of the extender after freezing-thawing, and before the straws were plunged into the liquid nitrogen. The females belonged to a synthetic commercial line selected for maternal characteristics [4].

\subsection{Semen collection and evaluation}

Two ejaculates per male and per week were collected using an artificial vagina. The following measurements were taken from fresh sperm:

- Volume: was measured in a graduated conical tube.

- Motility: a dilution of 1:50 with a triscitric acid-glucose extender was made to subjectively measure the percentage of motile sperm. Motility was examined at $37{ }^{\circ} \mathrm{C}$ under a microscope with phase contrast optics, at $125 \mathrm{X}$, and connected to a monitor through a camera. Only those ejaculates with more than $70 \%$ motile sperm were used in the experiment.

- Concentration: one sample was fixed in a solution of glutaraldehyde, and concentration was measured using a ThomaZeiss counting cell chamber.

- Morphological examination: the percentage of spermatozoa with a normal apical ridge, cytoplasmatic droplets or abnormal spermatozoa were measured in a sample fixed with glutaraldehyde, at a magnification of $400 \times$ with a differential interference contrast microscope (Nomarski contrast). 
In the cooled or frozen semen, motility and acrosomal integrity estimations were made in the same way as for fresh semen.

\subsection{Freezing protocol}

The extender to dilute the fresh sperm (extender 1) had the following composition: $0.25 \mathrm{M}$ of Tris[hydroxymethyl]aminomethane (Sigma), $88 \mathrm{mM}$ of anhydrous citric acid (Sigma), and $47 \mathrm{mM}$ of D (+) glucose (Sigma) [21].

The freezing extender was composed of extender 1 and $3.5 \mathrm{M}$ of dimethyl sulfoxide (DMSO, Sigma) and 0.1 M of sucrose (Sigma) were added as cryoprotectants [19].

Once the concentration $\left(10^{6}\right.$ spermatozoa $\cdot \mathrm{mL}^{-1}$ ) was known, the sperm were diluted with the extender 1 to obtain 120 million sperm $\cdot \mathrm{mL}^{-1}$.

After that, 60 million sperm/male $\left(0.5 \mathrm{~mL}\right.$ of semen at 120 million sperm. $\left.\mathrm{mL}^{-1}\right)$ were kept for the inseminations with fresh sperm, and they were diluted 1:1 with the extender 1 to have 60 million sperm $\cdot \mathrm{mL}^{-1}$. The rest of the semen was diluted with the freezing extender (dilution 1:1) at room temperature, for 60 million sperm. $\mathrm{mL}^{-1}$, the final concentrations of the cryoprotectants were $0.05 \mathrm{M}$ sucrose and $1.75 \mathrm{M}$ DMSO. The sperm was packaged in $0.5 \mathrm{~mL}$ plastic straws, and sealed with modelling paste; after that, they were put in a fridge at $5{ }^{\circ} \mathrm{C}$ for $45 \mathrm{~min}$, and later placed in a freezer at $-30{ }^{\circ} \mathrm{C}$ for $30 \mathrm{~min}$ before they were plunged into the liquid nitrogen.

\subsubsection{Experiment 1}

To study if the cryoprotectants were toxic after the cooling phase of the protocol (after the sperm had been at $5{ }^{\circ} \mathrm{C}$ for $45 \mathrm{~min}$ ), a total of 22 receptive females were inseminated with 30 million cooled sperm $(0.5 \mathrm{~mL}$ of sperm/female) and another 23 females were inseminated with fresh sperm to compare the results; four replicates were done
(12 females/day, inseminating 2 females/ male for fresh sperm and 2 females/male for cooled sperm). One of the females which had been inseminated with cooled sperm was eliminated from the analysis due to reproductive problems.

\subsubsection{Experiment 2}

To study if the results were comparable to those obtained with fresh sperm after the freezing phase of the protocol (after $45 \mathrm{~min}$ at $5^{\circ} \mathrm{C}$ and $30 \mathrm{~min}$ at $-30^{\circ} \mathrm{C}$, and before being plunged into liquid nitrogen), the sperm was taken from the freezer and thawed at $50{ }^{\circ} \mathrm{C}$ for $15 \mathrm{~s}$; after that, 36 females were inseminated with 30 million of frozen (18 does) or fresh sperm (18 does). The experiment was replicated 3 times, inseminating 12 females/day ( 2 females/male/day for fresh sperm and another 2 for frozen sperm)

In both experiments, only those females which were receptive (checking the vulva colour), were inseminated. Insemination was carried out with a curved glass pipette (0.5 mm diameter). To induce ovulation, females were injected intramuscularly with $1 \mu \mathrm{g}$ of busereline acetate (Hoechst Marion Roussel, S.A.) at the same time as insemination was performed. All inseminated does were nonlactating multiparous females.

\subsection{Embryo recovery}

Females were slaughtered 48 hours after they had been inseminated. The reproductive tract was removed, ovulation rate was noted and the embryos were recovered by flushing each oviduct (and a little part of the uterus) with $5 \mathrm{~mL}$ of Dulbecco Phosphate-buffered saline (DPBS, Sigma), supplemented with $0.132 \mathrm{~g} \cdot \mathrm{L}^{-1}$ of calcium chloride dihydrate (Sigma). Embryos were classified according to morphological criteria [7]; only those embryos in the 8 cell or 16 cell stages were considered as normal. The number of 
oocytes, normal and abnormal embryos were noted.

The following parameters were calculated: total recovered (oocytes + normal embryos + abnormal embryos), number of total embryos (normal embryos + abnormal embryos), total recovery success (total recovered/ovulation rate), normal embryo recovery success (normal embryos/ovulation rate), percentage of normal embryos compared with the number of total embryos (normal embryos/total embryos) and normal embryos compared with the total recovered (normal embryos/total recovered).

\subsection{Statistical analysis}

A chi-squared test with the Yate correction (Statgraphics Plus 1994-1999) [17] was used to analyse fertility rate, using the semen treatment (fresh or cooled and fresh or frozen) as factors, because no effects of the male were found on fertility rate.

Only those females which had at least one embryo were used in the analysis of embryo recovery. The statistical analysis employed was a General Linear Model (GLM) of SAS (Statistical Analysis System Institute, 1997) [15]. For Experiment 1, semen treatment was employed as the fixed effect to analyse the number of oocytes and abnormal recovered embryos, and for the analysis of normal embryos, total recovered (normal and abnormal embryos and oocytes) and total embryos recovered (normal and abnormal) ovulation rate was employed as the covariate. Fertility rate (number of normal embryos/number of total embryos and oocytes), percentage of normal embryos (normal embryos/total embryos), recovery success (total recovered/ovulation rate), and normal embryo recovery success (normal embryos/ovulation rate) were analysed with a GLM, using the treatment of the sperm as the fixed effect.

\section{RESULTS}

The results of fertility rate and the number of oocytes and embryos recovered for Experiment 1 are represented in Table I. There were no significant differences in the percentage of females fertilised between sperm treatments, between female lines or between males. There were no differences either in the rest of the parameters studied.

In Table II, the results for the parameters of recovery success are represented. As can be seen, there were no differences between fresh and cooled sperm for any of the ratios calculated.

There were no differences between treatments in the normal acrosome rate $(85 \%$ for fresh semen and $80 \%$ for cooled sperm) and motility ( $85 \%$ for fresh semen and $78 \%$ for cooled sperm). The results obtained for fresh sperm compared to frozen sperm are

Table I. Results of embryo production for fresh and cooled sperm (experiment 1).

\begin{tabular}{|c|c|c|c|c|c|c|c|c|}
\hline \multirow[t]{2}{*}{ Semen } & \multirow[t]{2}{*}{$\mathrm{Nb}$. } & \multirow{2}{*}{$\begin{array}{l}\text { Fertility } \\
\text { (nb) }\end{array}$} & \multirow{2}{*}{$\begin{array}{l}\text { Ovul. } \\
\text { (mean) }\end{array}$} & \multirow{2}{*}{$\begin{array}{c}\text { Total } \\
\text { recovered } \\
\text { (LSM } \pm \text { s.e.) }\end{array}$} & \multirow{2}{*}{$\begin{array}{c}\text { Oocytes } \\
(\mathrm{LSM} \pm \text { s.e. })\end{array}$} & \multicolumn{3}{|c|}{ Embryos } \\
\hline & & & & & & $\begin{array}{c}\text { Total } \\
(\mathrm{LSM} \pm \text { s.e. })\end{array}$ & $\begin{array}{c}\text { Normal } \\
(\mathrm{LSM} \pm \text { s.e. })\end{array}$ & $\begin{array}{c}\text { Abnormal } \\
(\mathrm{LSM} \pm \text { s.e. })\end{array}$ \\
\hline & 23 & $78 \%(18$ & $2.0 \pm 0.49$ & $8.3 \pm 0.78$ & & $7.0 \pm 0.86$ & & \\
\hline Cooled & 22 & $91 \%(20)$ & $12.1 \pm 0.5$ & $9.0 \pm 0.74$ & $0.1 \pm 0.46$ & $8.9 \pm 0.82$ & $8.5 \pm 0.86$ & $0.5 \pm 0.20$ \\
\hline Total & 45 & $84 \%(38)$ & $12.1 \pm 0.35$ & $8.7 \pm 0.53$ & $0.7 \pm 0.34$ & $8 \pm 0.61$ & $7.7 \pm 0.63$ & $0.3 \pm 0.14$ \\
\hline
\end{tabular}

Nb.: number of females. Ovul.: Ovulation Rate. Total recovered: normal embryos + abnormal embryos + oocytes. Oocytes: number of recovered oocytes. Embryos: total: total recovered embryos (normal embryos + abnormal embryos); normal: number of normal embryos; abnormal: number of abnormal embryos. 
summed up in Table III. Significant differences between fresh and frozen sperm in the total recovered, total embryos recovered and number of normal embryos were observed, with fresh sperm having higher values for all the parameters studied.

As may be seen in Table IV, the percentage of normal embryos from total recovery was higher for fresh than for frozen sperm, because in females inseminated with frozen sperm, a higher number of oocytes were obtained as can be seen in Table III.
Less total recovery (oocytes and embryos) was obtained in the group of females inseminated with frozen sperm than with fresh sperm.

It is interesting that no differences were observed between males in any of the parameters studied when working with fresh sperm. Nevertheless, differences between the males were observed (perhaps because of a different resistance to freezing) when working with frozen sperm in the number of total embryos recovered (only 1.7 embryos

Table II. Recovery results for fresh and cooled sperm (experiment 1).

\begin{tabular}{lcccc}
\hline Semen & $\begin{array}{c}\text { Normal } \\
\text { embryos/total } \\
\text { recovered (mean) }\end{array}$ & $\begin{array}{c}\text { Normal } \\
\text { embryos/total } \\
\text { embryos (mean) }\end{array}$ & $\begin{array}{c}\text { Total recovered/ } \\
\text { ovulation (mean) }\end{array}$ & $\begin{array}{c}\text { Normal } \\
\text { embryos/ovulation } \\
\text { (mean) }\end{array}$ \\
\hline Fresh & $81 \%$ & $94 \%$ & $69 \%$ & $58 \%$ \\
Cooled & $92 \%$ & $92 \%$ & $75 \%$ & $70 \%$ \\
Total & $86 \%$ & $93 \%$ & $72 \%$ & $64 \%$ \\
\hline
\end{tabular}

Table III. Results of embryo production for fresh and frozen sperm (experiment 2).

\begin{tabular}{|c|c|c|c|c|c|c|c|c|}
\hline \multirow[t]{2}{*}{ Semen } & \multirow[t]{2}{*}{$\mathrm{Nb}$. } & \multirow{2}{*}{$\begin{array}{l}\text { Fertility } \\
\text { (nb) }\end{array}$} & \multirow{2}{*}{$\begin{array}{l}\text { Ovul. } \\
\text { (mean) }\end{array}$} & \multirow{2}{*}{$\begin{array}{c}\text { Total } \\
\text { recovered } \\
(\mathrm{LSM} \pm \text { s.e. })\end{array}$} & \multirow{2}{*}{$\begin{array}{c}\text { Oocytes } \\
(\mathrm{LSM} \pm \text { s.e. })\end{array}$} & \multicolumn{3}{|c|}{ Embryos } \\
\hline & & & & & & $\begin{array}{c}\text { Total } \\
(\mathrm{LSM} \pm \text { s.e. })\end{array}$ & $\begin{array}{c}\text { Normal } \\
(\mathrm{LSM} \pm \text { s.e. })\end{array}$ & $\begin{array}{c}\text { Abnormal } \\
(\mathrm{LSM} \pm \text { s.e. })\end{array}$ \\
\hline Can & 18 & $94 \%$ a $(1$ & $2.6 \pm 0.6$ & $9.7 \pm 0.53^{\mathrm{a}}$ & $0.5 \pm 0.57$ & $9.2 \pm 0.62^{\mathrm{a}}$ & $7.8 \pm 0.85^{\mathrm{a}}$ & $1.4 \pm 0.51$ \\
\hline Frozen & 18 & $61 \%^{\mathrm{b}}(11)$ & $12.4 \pm 0.74$ & $7.1 \pm 0.66^{b}$ & $2.4 \pm 0.71$ & $4.7 \pm 0.77^{b}$ & $3.8 \pm 1.05^{\mathrm{b}}$ & $0.9 \pm 0.64$ \\
\hline
\end{tabular}

Nb.: number of females. Ovul.: ovulation rate. Total recovered: normal embryos + abnormal embryos + oocytes. Oocytes: number of recovered oocytes. Total embryos: total recovered embryos (normal embryos + abnormal embryos). Total normal: number of normal embryos. Total abnormal: number of abnormal embryos.

a,b Values in the same column with different superscripts differ statistically $(P<0.05)$.

Table IV. Recovery results for fresh and frozen sperm (experiment 2).

\begin{tabular}{lcccc}
\hline Semen & $\begin{array}{c}\text { Normal } \\
\text { embryos/total } \\
\text { recovered (mean) }\end{array}$ & $\begin{array}{c}\text { Normal } \\
\text { embryos/total } \\
\text { embryos (mean) }\end{array}$ & $\begin{array}{c}\text { Total recovered/ } \\
\text { ovulation (mean) }\end{array}$ & $\begin{array}{c}\text { Normal } \\
\text { embryos/ovulation } \\
\text { (mean) }\end{array}$ \\
\hline Fresh & $79 \%^{\mathrm{a}}$ & $83 \%$ & $79 \%$ & $63 \%^{\mathrm{a}}$ \\
Frozen & $55 \%^{\mathrm{b}}$ & $67 \%$ & $57 \%$ & $29 \%^{\mathrm{b}}$ \\
\hline
\end{tabular}

a,b Values in the same column with different superscripts differ statistically $(P<0.05)$. 
for one male and between 6 and 6.7 for the other two males), since more oocytes were obtained when females were inseminated with frozen sperm from one male (5.26 oocytes for this male and 0 oocytes when the other males' sperm was used). No differences were observed, however, between males for motility or the percentage of intact acrosomes after freezing-thawing (between 40 and $60 \%$ motility rate and $62-78 \%$ normal apical ridge).

Significant differences between fresh and frozen sperm were obtained for motility (92\% vs. 52\% for fresh and frozen sperm, respectively) and percentage of spermatozoa with intact acrosomes ( $94 \%$ vs. $71 \%$ for fresh and frozen sperm, respectively).

\section{DISCUSSION}

As can be seen on Tables 1 and 2, the fertilising ability of both fresh and cooled sperm was similar, since no differences were observed in the number of embryos that they produced; this could be due to the similar quality between both types of sperm. So when this extender for freezing rabbit sperm is used, the bad results that are obtained post-thawing, after insemination of females on commercial farms $(50 \%$ of fertility rate and 6.9 total born, [10]) do not seem to be due to a toxic effect of DMSO when sperm is processed at room temperature. It seems that enough numbers of spermatozoa are able to reach the oviducts (or there are no problems in the transport of sperm), since the oocytes were fertilised at the same level when cooled sperm were used as when fresh sperm were used, but it would probably be good to know if the accessory spermatozoa are the same in both groups (because they represent potential fertilising sperm that are able to complete all the necessary events to fertilise oocytes, [5]). The results obtained were in agreement with those obtained by Stranzinger et al. [18] working with sperm which had been diluted with a tris-egg yolkDMSO extender (final concentration of DMSO: $12.5 \%$ ), and which had been stored for 6 or $8 \mathrm{~h}$ at $5{ }^{\circ} \mathrm{C}$ before being used for insemination; the percentage of does kidding was $67 \%$, with 6.5 rabbits/female kidding, but no females were inseminated with fresh sperm for comparison. Maurer et al. [9], used the same extender as Stranzinger et al. [18], and they compared the results for sperm which had been stored for $5 \mathrm{~h}$ at $37^{\circ} \mathrm{C}$ or $5^{\circ} \mathrm{C}$; they induced ovulations $5 \mathrm{~h}$ before they inseminated, and they did not observe any difference in the percentage of cleaved embryos (recovered $32 \mathrm{~h}$ after insemination) between sperm which had been stored at $37{ }^{\circ} \mathrm{C}(81 \%)$ or $5{ }^{\circ} \mathrm{C}(87 \%)$, nor in the percentage of blastocysts recovered $\left(68 \%\right.$ for sperm at $37{ }^{\circ} \mathrm{C}$ and $62 \%$ for sperm at $5{ }^{\circ} \mathrm{C}$ ), but there seemed to be a delay in the development of embryos produced by sperm stored at $5{ }^{\circ} \mathrm{C}$, since only $59 \%$ of the blastocysts recovered were classified as normal $\left(81 \%\right.$ for sperm at $\left.37^{\circ} \mathrm{C}\right)$, but $68 \%$ of the foetuses were recovered at term (and $64 \%$ for sperm at $37^{\circ} \mathrm{C}$ ). It could be concluded from the work of Maurer et al. [9] that rabbit sperm does not lose its fertilising ability even when stored with DMSO at $37^{\circ} \mathrm{C}$, so it is logical that we did not find any bad effects produced by DMSO after loading the straws at room temperature.

However, the differences between these treatments may have been on early embryo mortality (due to a toxic effect of DMSO, which has been seen in other species by other authors, [13]) instead of on fertilising ability. We could not appreciate this, however, because the females were slaughtered only 48 hours after being inseminated. O'Shea and Wales [13], observed a similar behaviour between fresh and frozen sperm when embryos were recovered $32 \mathrm{~h}$ postinsemination $(88 \%$ of the total recovered were normal embryos for fresh sperm and $79 \%$ for frozen sperm), and they only observed differences between sperm when females were slaughtered 15 days after insemination (77\% of implanted embryos for fresh sperm and $49 \%$ for frozen sperm), because there was a higher mortality in females that had been inseminated with frozen sperm. 
Concerning the frozen sperm, it can be seen that a lower total recovery (oocytes + embryos) was obtained from does inseminated with frozen sperm than with fresh semen, maybe due to a more rapid transport of the oocytes than the embryos. At the same time, fewer embryos were recovered from does inseminated with frozen sperm than with fresh sperm. Vicente and Viudes de Castro [19], working with the same extender, obtained more normal embryos recovered with frozen sperm ( 8.9 vs. 3.8 obtained in the present work), and the percentage of normal embryos from total recovery was also higher in their work $(76 \%)$, than in the present study (57\%), but they obtained more oocytes working with frozen than with fresh sperm, as observed in the present work; these different results could be due to a change in the freezer used, or to a change in the straws used $(0.25 \mathrm{~mL}$ to $0.5 \mathrm{~mL})$. O'Shea and Wales [13] observed 78\% cleaved embryos after $30 \mathrm{~h}$ post-insemination (in the present study, only $29 \%$ of normal embryos were recovered from the ovulation rate), but they observed only $49 \%$ of developing embryos after 15 days postinsemination. In this study, $55 \%$ of normal embryos were recovered referred to total recovered when working with frozen sperm (Tab. IV), which was in agreement with the results reported by Maurer et al. [9], who observed a $45 \%$ cleavage rate (from total recovery) when inseminating with frozen sperm. The low number of total embryos recovered could indicate a problem in the transport of sperm (very few sperm are able to reach the oviducts to fertilise oocytes, although Murdoch and O'Shea, [12], observed fewer sperm in the oviducts of females inseminated with frozen sperm, but the differences between fresh and frozen sperm were not significant) since other authors have reported fewer accessory sperm in oocytes from females inseminated with frozen sperm [9, 12, 14]. This could also indicate a very low viability of the spermatozoa (they could reach the oviducts, but they would remain alive for a very short time) or any other problems which could prevent them fertilising (premature acrosome reactions or capacitation-like patterns, for example). To solve some of these problems, a higher number of sperm could be used for insemination, or an asynchrony between ovulation and insemination could be introduced.

As could be seen, no effect of the cooling phase of the freezing protocol on fertility rate and the number of normal embryos was observed. Nevertheless, when working with frozen sperm (after straws had completed the freezing protocol, but before they were plunged into liquid nitrogen), both fertility rate and the number of normal embryos recovered were significantly different from those obtained when inseminating with fresh semen, which indicates that the differences obtained between fresh and frozen sperm are produced during the second phase of the freezing protocol.

Future studies on the effect of DMSO on embryo and foetal survival would be of interest. To try to improve the results obtained with the sperm frozen with this protocol, it would be interesting to introduce asynchronies between ovulation and insemination, since other authors have observed better results when insemination was performed at different times after ovulation was induced [18], if it is supposed that freezing and thawing may alter the capacitation time, allowing sperm to capacitate faster [14].

\section{ACKNOWLEDGMENTS}

This study was supported by CYCIT AGF980470-C02-01. The authors thank Mr Neil Macowan for revising the English version. We would like to thank to Lorena Mocé for statistical assistance.

\section{REFERENCES}

[1] Arriola J., Foote R.H., Accessory sperm as an indication of fertilizing ability of rabbit spermatozoa frozen in egg yolk-acetamide with detergent, J. Androl. 22 (2001) 458-463. 
[2] Bamba K., Adams C.E., Freezing rabbit semen by the use of BF5 diluent, Lab. Anim. 24 (1990) 172-175.

[3] Dalimata A.M., Graham J.K., Cryopreservation of rabbit spermatozoa using acetamide in combination with trehalose and methyl cellulose, Theriogenology 48 (1997) 831-841.

[4] Estany J., Baselga M., Blasco A., Camacho J., Mixed model methodology for estimation of genetic response to selection in litter size in rab bits, Livest. Prod. Sci. 21 (1989) 67-75.

[5] Evenson D.P., Loss of livestock breeding efficiency due to uncompensable sperm nuclea defects, Reprod. Fertil. Dev. 11 (1999) 1-15.

[6] Fox R.R., Preservation of rabbit spermatozoa: fertility results from frozen semen, Proc. Soc. Exp. Biol. Med. 108 (1961) 663-665.

[7] Hafez E.S.E., Preservation and cryopreservation of gametes and embryos, in: Hafez E.S.E. (Ed.), Reproduction in Farm Animals, 6th ed. Lea and Febiger, Philadelphia, 1993 pp. 503-526.

[8] Hanada A., Nagase H., Cryoprotective effects of some amides on rabbit spermatozoa, J. Reprod. Fertil. 60 (1980) 247-252.

[9] Maurer R.R., Stranzinger G.F., Paufler S.K. Embryonic development in rabbits after insemination with spermatozoa stored at 37,5 or $-196^{\circ} \mathrm{C}$ for various periods, J. Reprod. Fertil. 48 (1976) 4-49.

[10] Mocé E., Vicente J.S., Test homólogo de penetración zonal para evaluar semen fresco y congelado de conejo, III Congreso Ibérico de Reproducción Animal, Oporto, 2001, pp. 415-420.

[11] Mocé E., Vicente J.S., Lavara R., Effect of donor strain and maturation stage of rabbit oocytes on results of penetration test of rabbit semen, World Rabbit Sci. 10 (2002) 53-62.
[12] Murdoch B.E., O'Shea T., Effect of storage of rabbit spermatozoa at $-79^{\circ} \mathrm{C}$ on their subsequent transport and fertility in the rabbit doe, Aust. J. Biol. Sci. 26 (1973) 645-651.

[13] O'Shea T., Wales R.G., Further studies of the deep freezing of rabbit spermatozoa in reconstituted skim milk powder, Aust. J. Biol. Sci. 22 (1969) 709-719.

[14] Parrish J.J., Foote R.H., Fertility of cooled and frozen rabbit sperm measured by competitive fertilization, Biol. Reprod. 35 (1986) 253-257.

[15] SAS 1997, SAS/STAT User's Guide (Release 6.03), SAS Inst, Cary, NC.

[16] Sawada Y., Chang M.C., Motility and fertilizing capacity of rabbit spermatozoa after freezing in a medium containing Dimethyl Sulfoxide, Fertil. Steril. 15 (1964) 222-229.

[17] STATGRAPHICS PLUS 4.1. 1994-1999.

[18] Stranzinger G.F., Maurer R.R., Paufler S.K., Fertility of frozen rabbit semen, J. Reprod. Fertil. 24 (1971) 111-113.

[19] Vicente J.S., Viudes-de-Castro M.P., A sucroseDMSO extender for freezing rabbit semen, Reprod. Nutr. Dev. 36 (1996) 485-492.

[20] Viudes-de-Castro M.P., Vicente J.S., A simple method for freezing rabbit semen with success ful results on fertility and prolificity, Anim. Reprod. Sci. 44 (1996) 195-201.

[21] Viudes-de-Castro M.P., Vicente J.S., Lavara R., Effet du nombre de spermatozoïdes sur la fertilité de la semence conservée 24 heures chez le lapin, Ann. Zootech. 48 (1999) 407-412.

[22] Weitze K.F., Hellemann C., Krause D., Insemination with rabbit semen frozen in plastic straws, 8th Int. Congr. Anim. Reprod. A.I. 2 (1976) 1100-1103. 